\title{
Halo Formation During Solidification of Refractory Metal Aluminide Ternary Systems
}

\begin{abstract}
N. D'SOUZA, L.M. FEITOSA, G.D. WEST, and H.B. DONG
The evolution of eutectic morphologies following primary solidification has been studied in the refractory metal aluminide (Ta-Al-Fe, Nb-Al-Co, and $\mathrm{Nb}-\mathrm{Al}-\mathrm{Fe}$ ) ternary systems. The undercooling accompanying solid growth, as related to the extended solute solubility in the primary and secondary phases can be used to account for the evolution of phase morphologies during ternary eutectic solidification. For small undercooling, the conditions of interfacial equilibrium remain valid, while in the case of significant undercooling when nucleation constraints occur, there is a departure from equilibrium leading to unexpected phases. In $\mathrm{Ta}-\mathrm{Al}-\mathrm{Fe}$, an extended solubility of $\mathrm{Fe}$ in $\sigma$ was observed, which was consistent with the formation of a halo of $\mu$ phase on primary $\sigma$. In Nb-Al-Co, a halo of C14 is formed on primary $\mathrm{CoAl}$, but very limited vice versa. However, in the absence of a solidus projection it was not possible to definitively determine the extended solute solubility in the primary phase. In $\mathrm{Nb}-\mathrm{Al}-\mathrm{Fe}$ when nucleation constraints arise, the inability to initiate coupled growth of $\mathrm{NbAl}_{3}+\mathrm{C} 14$ leads to the occurrence of a two-phase halo of $\mathrm{C} 14+\mathrm{Nb}_{2} \mathrm{Al}$, indicating a large undercooling and departure from equilibrium.
\end{abstract}

https://doi.org/10.1007/s11661-018-4519-1

(c) The Author(s) 2018. This article is an open access publication

\section{INTRODUCTION}

THE formation of a halo or growth of a secondary phase around the primary phase and thereby precluding coupled growth is a common occurrence in off-eutectic alloy compositions. ${ }^{[1]}$ One of the possible processing methods for the manufacture of components is via the liquid route, as it involves the extension of a well-established technology that permits components to be produced in a single-stage process. However in liquid-solid phase transformations, alloy compositions are restricted by the occurrence of appropriate phase equilibria that is dictated by thermodynamic as well as kinetic considerations. The latter specifically plays a key role in the evolution of phase morphologies for eutectic or near-eutectic compositions, such as in in situ composites, where fine-coupled eutectic structures are desirable over coarser dendritic structures (or halos) for superior mechanical properties. ${ }^{[2]}$ Therefore, it becomes important to study the conditions under which the

N. D'SOUZA is with Rolls-Royce plc, PO. Box 31, Derby DE24 8BJ, UK; L.M. FEITOSA, and H.B. DONG are with the Department of Engineering, University of Leicester, Leicester, LE1 7RH, UK, Contact e-mail: h.dong@le.ac.uk G.D. WEST is with the Warwick Manufacturing Group, University of Warwick, Coventry CV4 7AL, UK.

Manuscript submitted September 19, 2017.

Article published online February 22, 2018 fine-structure-coupled eutectic prevails over the coarser dendritic structures or halos during solidification.

The aim of this paper is to investigate the formation of halos in some typical ternary systems. The refractory metal aluminide (RM-Al-X) systems are specifically chosen, since they have been considered as alternative materials for high-temperature applications. Typically, $\mathrm{RM}=\mathrm{Ta}$ and $\mathrm{Nb}$ and $X=\mathrm{Co}$, Fe. The high-temperature strength in these systems is derived through the presence of super-lattice precipitates, i.e., $\mathrm{A} 2+\mathrm{B} 2$ or $\mathrm{A} 2+\mathrm{L} 2{ }_{1}$ phase mixtures, where $\mathrm{A} 2$ is bcc-disordered matrix, while the precipitates are super-lattice, i.e., B2, $\mathrm{CsCl}$ structure or $\mathrm{L}_{1}$, the Heusler phase, ${ }^{[3,4]}$ while the role of $\mathrm{Al}$ is to impart oxidation resistance through the formation of a continuous layer of $\mathrm{Al}_{2} \mathrm{O}_{3} \cdot{ }^{[5-7]}$ The typical applications of these alloys are above $1000{ }^{\circ} \mathrm{C}$ and finds use in structural applications. As an example, research investigating intermetallic Laves phase alloys has shown improved strength above $1273 \mathrm{~K}\left(1000{ }^{\circ} \mathrm{C}\right) .^{[8,9]}$

In equiaxed solidification, halo formation has been interpreted on the basis of non-reciprocal nucleation. ${ }^{[10]}$ This can be illustrated as follows - in Figure 1(a), $\beta$ phase nucleates on $\alpha$ phase with undercooling, $\Delta T_{\beta \alpha}$, but $\alpha$ phase nucleation on primary $\beta$ requires a greater undercooling, $\Delta T_{\alpha \beta}$. Therefore, when a hyper-eutectic alloy of nominal composition $C_{2}$ is cooled from the liquid state, $\beta$ phase forms from the liquid and on cooling to $T_{\alpha \beta}, \alpha$ phase nucleates at an undercooling, $\Delta T_{\alpha \beta} . \alpha$ phase grows around $\beta$ phase as a halo. Subsequent growth of $\alpha$ phase returns the liquid 


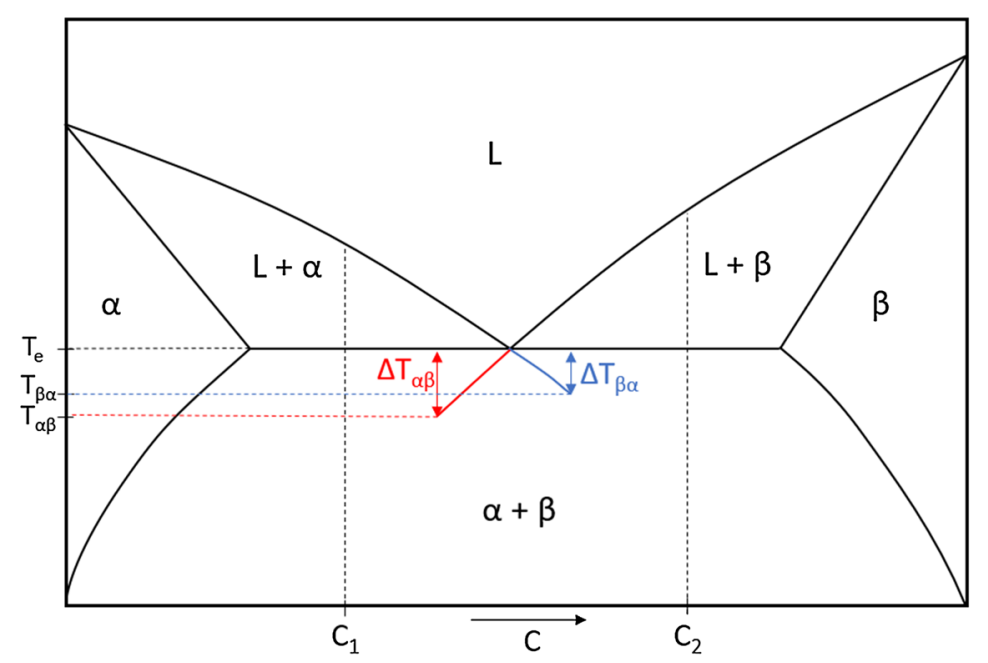

(a)

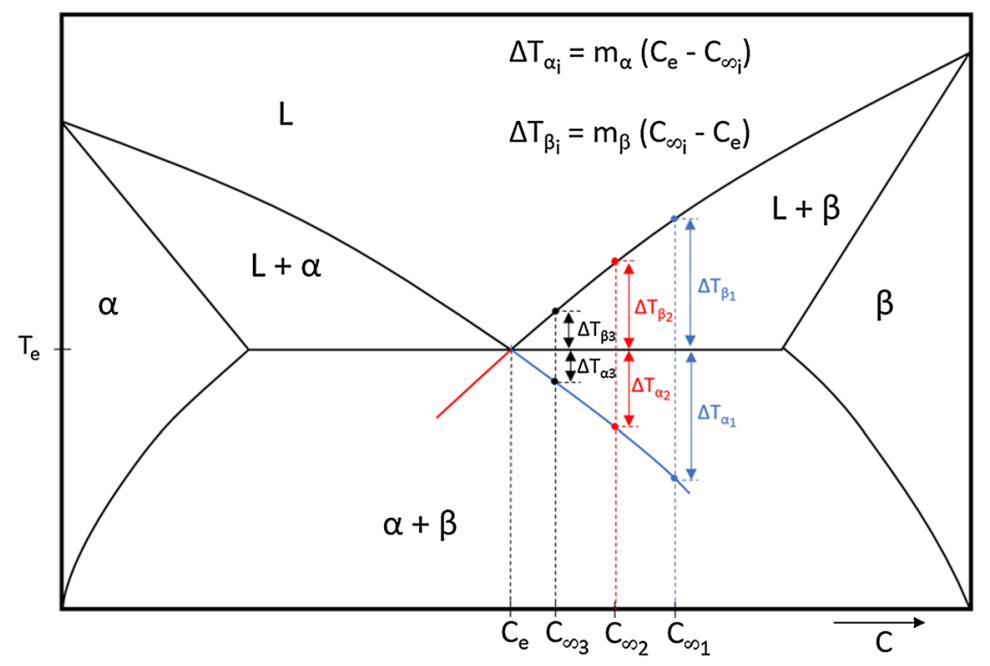

(b)

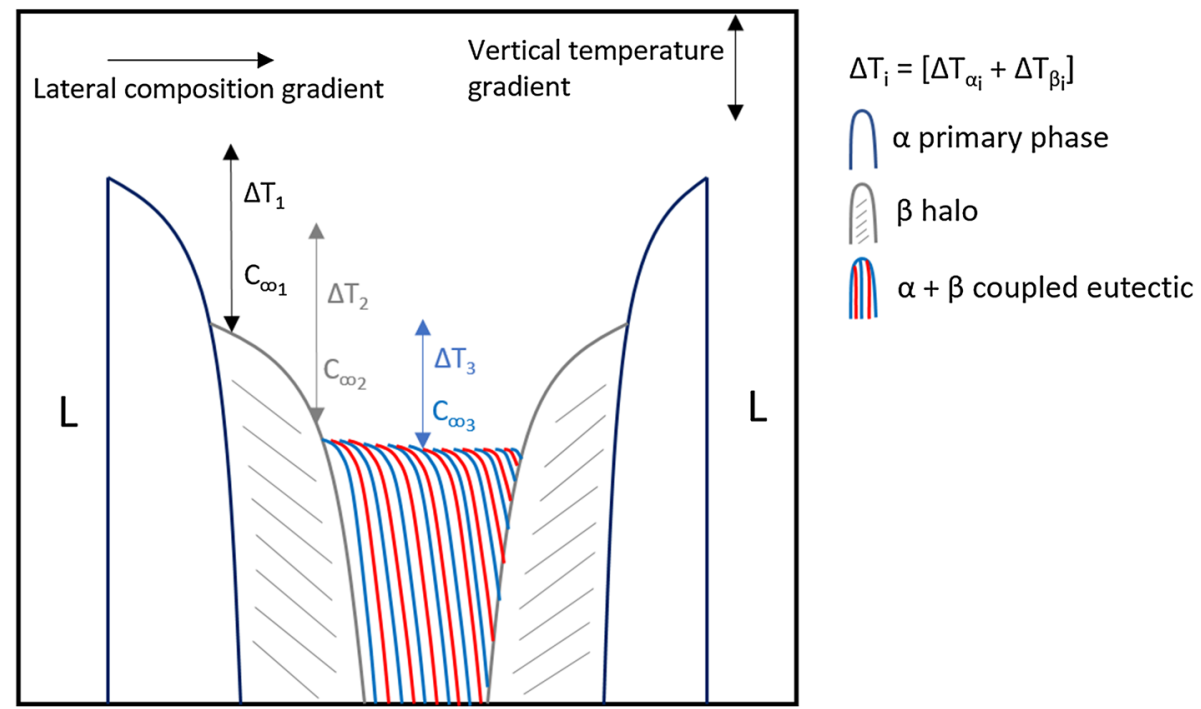

(c) 
Fig. 1-Schematic illustration for formation of halos in a binary system, (a) role of nucleation undercooling, where $\alpha$ phase is a good nucleant for $\beta$ phase, but $\beta$ phase is not a good nucleant for $\alpha$ phase in equiaxed solidification, $(b)$ directional solidification showing the undercooling at the growing tips of the halo phase and that required for coupled planar eutectic growth, (c) schematic evolution of the secondary phase morphology in the inter-dendritic region and the existence of a lateral composition gradient. composition back to $C_{\mathrm{e}}$ and release of latent heat results in the liquid temperature reaching $T_{\mathrm{e}}$, when coupled eutectic growth occurs thereafter. The implicit assumption therefore is that coupled eutectic growth only occurs at a unique composition, $C_{\mathrm{e}}{ }^{[10]}$ It follows therefore that the size of the halo around the primary phase increases with increasing nucleation undercooling, i.e., deviation of the liquid composition from $C_{\mathrm{e}}$.

Table I. List of Samples, Elemental Composition, and Observed Phases in the Microstructure

\begin{tabular}{lllll}
\hline Sample ID & & Composition (Atom Percent) & Phases Observed \\
\hline & $\mathrm{Al}$ & $\mathrm{Fe}$ & $\mathrm{Ta}$ & $\sigma(\mathrm{p})+\mu$ \\
S1 & 20.3 & 23.0 & 56.7 & $\sigma(\mathrm{p})+\mu$ \\
S2 & 29.9 & 14.7 & 55.4 & $\mathrm{CoAl}(\mathrm{p})+\mathrm{C} 14$ \\
& $\mathrm{Al}$ & $\mathrm{Co}$ & $\mathrm{Nb}$ & $\mathrm{C} 14(\mathrm{p})+\mathrm{CoAl}$ \\
S3 & 41.0 & 45.2 & 13.8 & $\mathrm{NbAl}(\mathrm{p})+\mathrm{Nb}_{2} \mathrm{Al}+\mathrm{C}_{3}$ \\
S4 & 37.5 & 38.6 & $\mathrm{Fe}$ & \\
& $\mathrm{Al}$ & $\mathrm{Fe}$ & 33.9 &
\end{tabular}
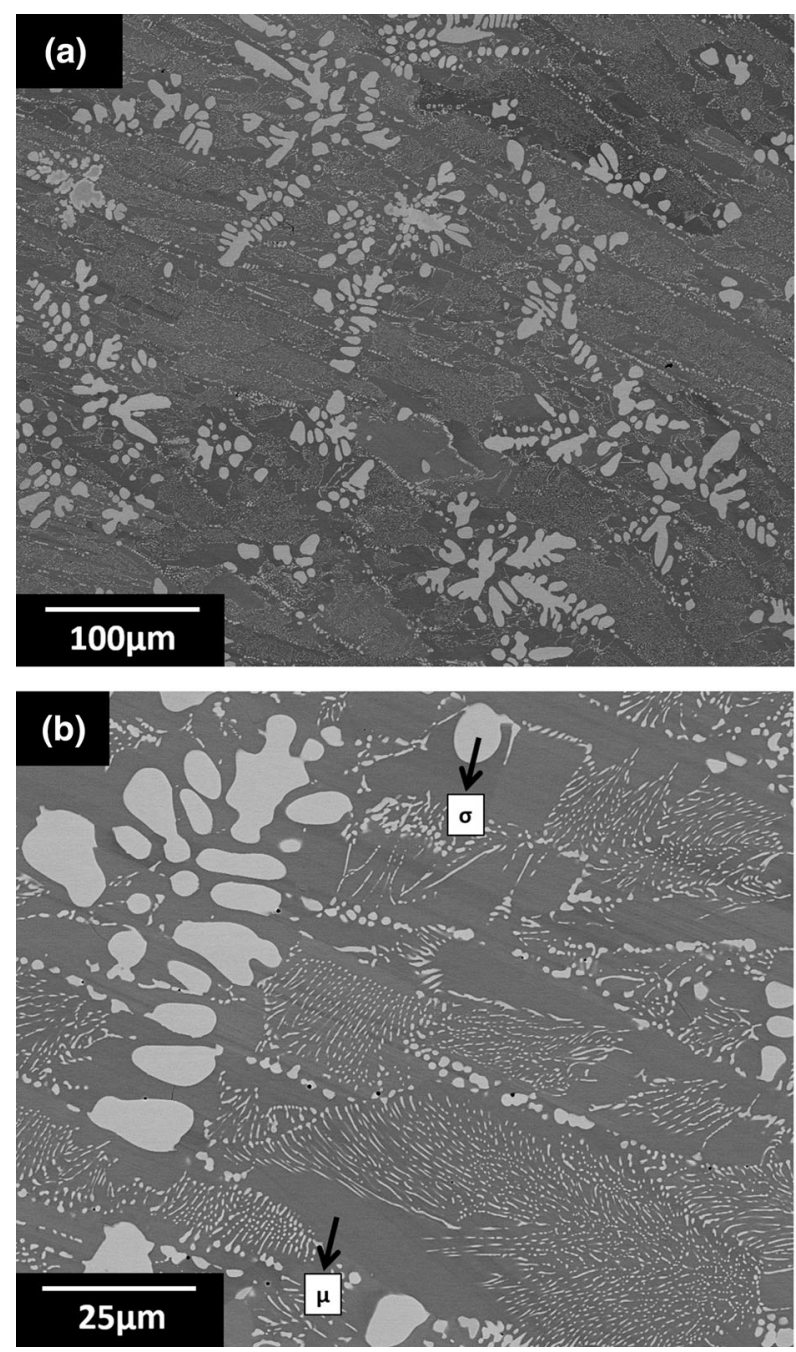
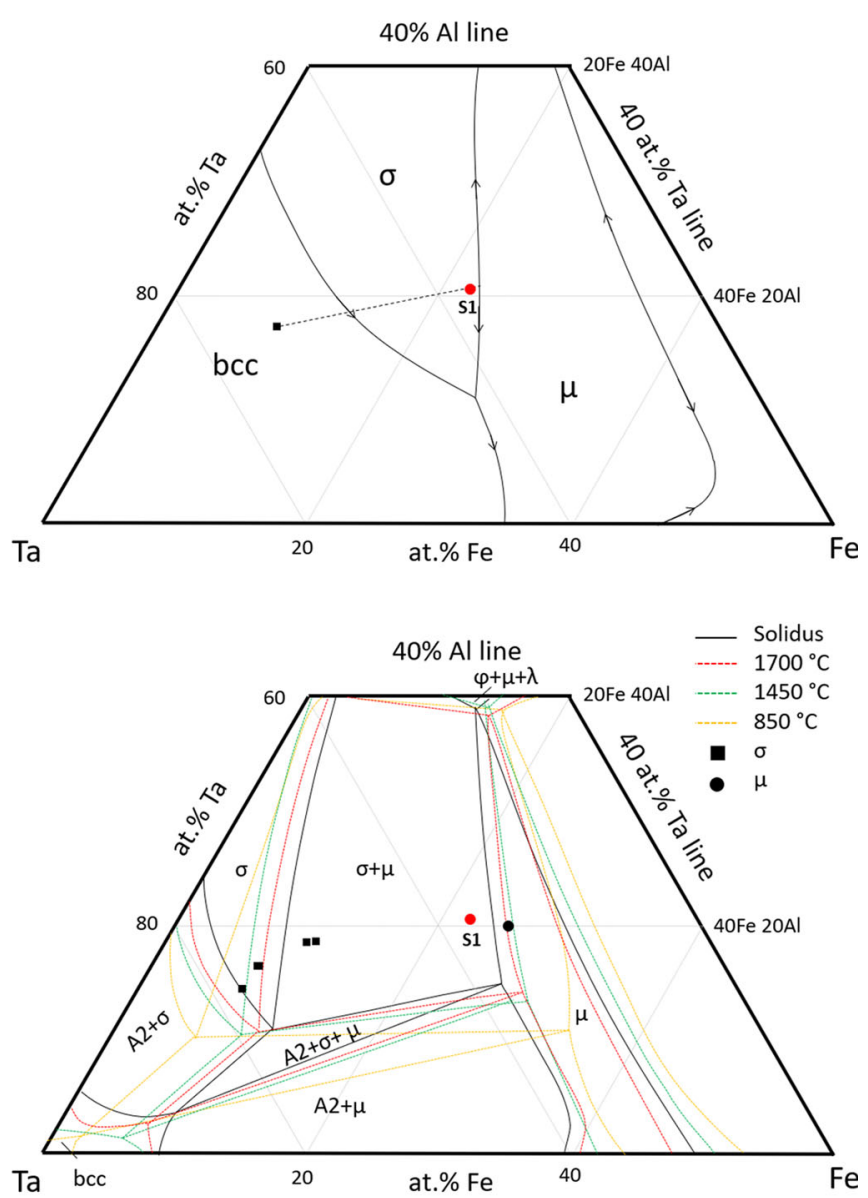

(c)

Fig. 2-Back-scattered electron images and liquidus and solidus projections corresponding to S1, $(a)$ low magnification, $(b)$ high magnification, (c) liquidus projection and solidus projections at Ta-rich end. Also included are phase boundaries with decreasing temperature and the measured composition in the phases. Reproduced with permission from Refs. [22] and [23]. 
However, it has been shown that coupled growth can in fact occur over a composition-temperature region, referred to as the coupled zone. ${ }^{[1]}$ In this case the selection of the morphology, i.e., halo (primary growth of secondary phase) or coupled eutectic is determined by the growth undercooling or growth kinetics. The halo phase will grow around the primary solid, if it grows at lower undercooling (or greater tip temperature) compared with the eutectic front for a given velocity. This is illustrated in Figure 1(b). For growth of the secondary phase as halo around the primary phase and corresponding to the liquid composition, $C_{\infty 1}$, the undercooling below the eutectic temperature is determined from the $\alpha$ liquidus extension and is given by, $\Delta \mathrm{T}_{\alpha 1}$. If $\beta$ phase forms from liquid composition, $C_{\infty 1}$, the undercooling for growth of $\beta$ phase must be calculated with respect to its equilibrium liquidus temperature and is given by, $\left[\Delta T_{\alpha 1}+\Delta T_{\beta 1}\right]$, where $\Delta T_{\beta 1}$ is the undercooling calculated with respect to the eutectic temperature, $\mathrm{T}_{\mathrm{e}}$, as shown in Figure 1(b). The growth velocity of $\beta$ phase (V) can be calculated from the local undercooling. ${ }^{[12]}$ On the other hand, if plane front coupled eutectic growth occurs, then it must do so with an undercooling, $\Delta T_{\alpha 1}=\Delta T_{\mathrm{e} 1}$ below the eutectic temperature and with a velocity, $V .{ }^{[13]}$ Therefore for a given undercooling below the eutectic temperature, $\Delta T_{\alpha 1}=\Delta T_{e 1}=m_{\alpha}\left(C_{e}-C_{\infty 1}\right)$, where $\mathrm{m}_{\alpha}$ (liquidus slope of $\alpha$ phase $)<0$. Here $C_{\mathrm{e}}$ is the invariant eutectic composition. A halo of $\beta$ phase forms around primary $\alpha$ phase if, $V>V^{\prime}$, while coupled eutectic growth occurs if $V<V^{\prime}{ }^{[14]}$ If a halo forms, then progressive growth of $\beta$ phase results in depletion of solute B in the liquid and consequently the liquid composition shifts progressively to $\mathrm{C}_{\infty 2}, \mathrm{C}_{\infty 3}, \ldots$, where $\mathrm{C}_{\infty 1}>\mathrm{C}_{\infty 2}>\mathrm{C}_{\infty 3}>\ldots$, as shown in Figure 1(b). At each successive liquid composition, there will be a decrease in equilibrium liquidus temperature for $\beta$ phase. This in turn results in decreased undercooling for continued halo growth, which in turn results in a lower growth velocity, $V$. Therefore at a certain liquid composition, $\mathrm{C}_{\infty \mathrm{i}}, \mathrm{V}<V^{\prime}$ and consequently coupled eutectic growth will be established in the liquid. This must result in the development of a lateral composition gradient in the liquid perpendicular to the growth direction, as indicated in Figure $1(\mathrm{~b}) \cdot{ }^{[14,15]}$ The evolution of the microstructure, i.e., growth of halo phase or coupled eutectic is schematically illustrated in Figure 1(c).

The formation of halos in binary systems under conditions of directional solidification have been well documented and temperature composition maps have been established for a range of alloy systems where the secondary phase grows as a halo phase and precluding coupled eutectic growth. ${ }^{[1-18]}$ However there are fewer investigations in ternary systems, where additional constraints occur.
- First, in ternary and higher order multi-component systems during primary growth the liquid composition unlike in the case of the binary case, is determined by a kinetic model. ${ }^{[19-21]}$ Therefore, it is not straightforward to determine $\Delta T_{\alpha 1}$.

- Second, in ternary systems de-stabilization of one or both phases can occur, since the partitioning of the third element will not be the same in both phases and a long-range diffusion layer is built-up. ${ }^{[11,14]}$

Accordingly, in this study we focus on some select compositions in the Ta-Al-Fe, Nb-Al-Co, and Nb-Al-Fe ternary systems produced by the arc melting process. The nominal compositions investigated are listed in Table I along with the phases that were observed in the microstructure based on detailed composition measurements and phase analysis using the liquidus projections, solidus projections, and isothermal sections.

\section{EXPERIMENTAL}

Samples were produced using arc melting, which involved melting of elemental powders on a cooled $\mathrm{Cu}$ hearth. With this method, small ingots of approximately $40 \mathrm{~g}$ of each alloy were cast via arc melting on a water-cooled hearth in an evacuated and argon backfilled atmosphere. Elemental metals with purity $\geq 99.9$ pct were used as the feedstock and to minimize the loss of $\mathrm{Al}$ during the melting process, the alloys were fabricated in a two-step procedure. A binary alloy was created from the refractory and transition metals, which was then melted with pure Al to create the final ingot. To increase the homogeneity of both the binary and ternary alloys, at least five re-melting operations were used at each stage in between which, the ingots were physically inverted on the hearth.

All scanning electron microscopy (SEM) was performed using a dual-beam Philips XL 30 ESEM. Back-scattered electron images (BSE) were collected using a retractable solid-state back-scatter detector using high $(20 \mathrm{kV})$ electron beam accelerating voltages for enhanced compositional contrast. Chemical analysis was undertaken in this system at $20 \mathrm{kV}$ using Energy Dispersive Spectroscopy (EDS).

\section{RESULTS}

In this section, the evolution of the different eutectic morphologies during solidification as well as the composition of the various phases in relation to their respective phase boundaries will be presented in detail.

Table II. Average Composition of Phases with Standard Deviation in S1 and S2 (in At Pet)

\begin{tabular}{lcrr}
\hline Phase & \multicolumn{1}{c}{ Pct Al } & \multicolumn{1}{c}{ Pct Fe } & Pct Ta \\
\hline$\sigma($ S1) & $16.1 \pm 1.81$ & $9.4 \pm 1.82$ & $74.5 \pm 3.63$ \\
$\mu$ (S1) & $20.0 \pm 0.10$ & $25.5 \pm 0.34$ & $54.6 \pm 0.26$ \\
$\sigma$ (S2) & $26.4 \pm 0.34$ & $6.7 \pm 0.26$ & $67.0 \pm 0.44$ \\
$\mu($ S2) & $31.6 \pm 0.32$ & $19.2 \pm 0.17$ & $49.2 \pm 0.15$ \\
\hline
\end{tabular}



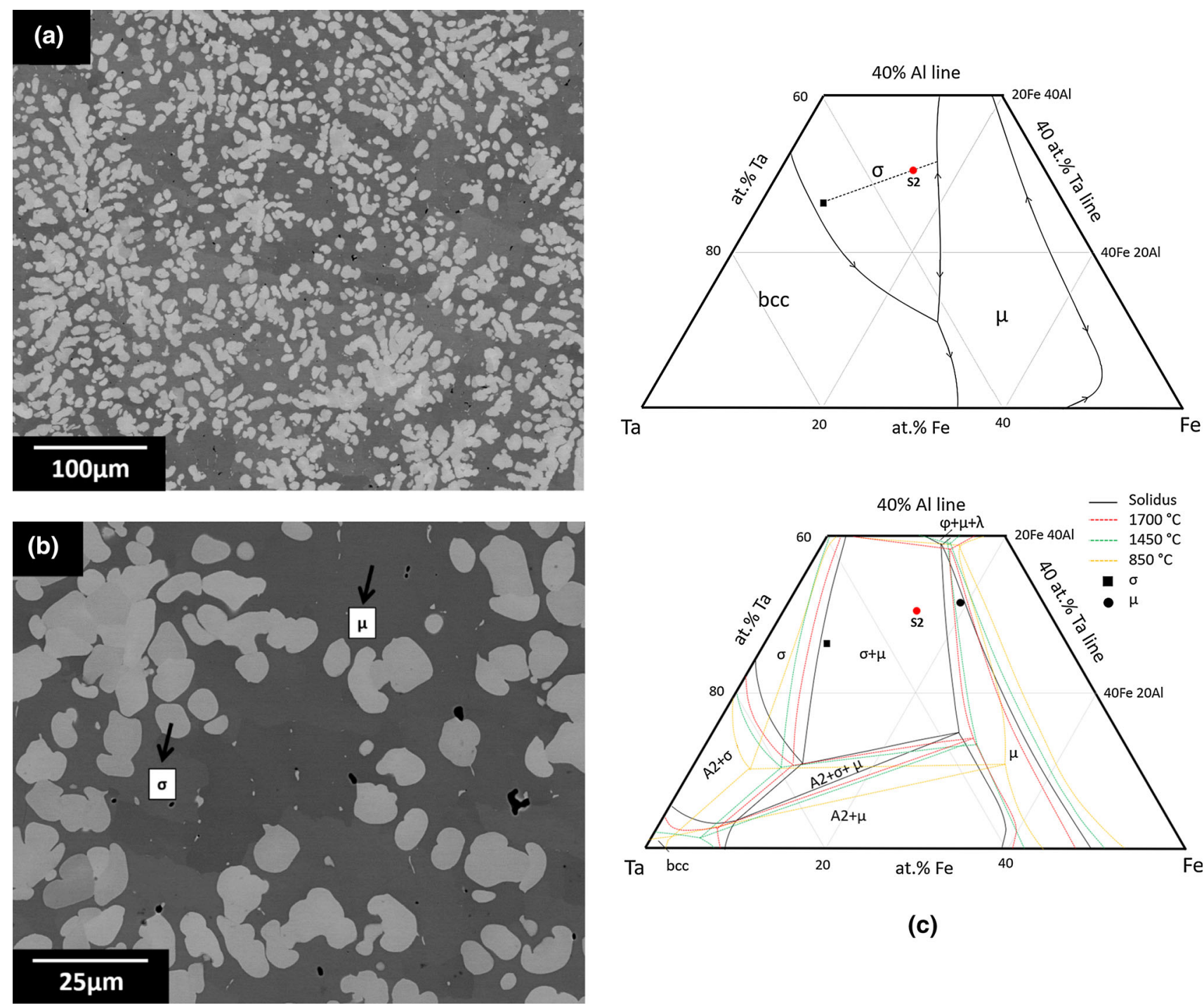

(c)

Fig. 3-Back-scattered electron images and liquidus and solidus projections corresponding to S2, $(a)$ low magnification, $(b)$ high magnification, (c) liquidus projection and solidus projections at Ta-rich end. Also included are phase boundaries with decreasing temperature and the measured composition in the phases. Reproduced with permission from Refs. [22] and [23].

S1 The solidification path of $\mathrm{S} 1$ is expected to follow, $L \rightarrow \sigma+L$ and $L \rightarrow \sigma+\mu$, following from the liquidus and solidus projections. ${ }^{[22,23]}$ Figures $2(\mathrm{a})$ and (b) are low- and high-magnification back-scattered electron images (BEI's), respectively, from which the following observations can be made:

(a) There is the occurrence of a limited extent of primary phase (bright contrast) having an irregular-shaped morphology. The inter-dendritic (ID) region comprises of a dark matrix phase along with the bright phase showing lamellar morphology. Some coarsening of the lamellae is also observed.

(b) The primary phase corresponds to $\sigma$, following from the composition measured at a number of locations across the primary globular phase (Table II) and the solidus projection. ${ }^{[22,23]}$ Micro-segregation occurs during primary freezing, as observed in the standard deviation in the measured $\sigma$ composition. An extended (increased) solubility of primarily $\mathrm{Fe}$ is observed in $\sigma$ from the solidus projection, as shown in Figure 2(c). This extended solute solubility cannot be accounted by solubility changes occurring during cooling, since the solidus surface of $\sigma$ enclosed by the $\sigma /[\sigma+\mu]$ and $\sigma /[\sigma+\mathrm{A} 2]$ boundaries shifts to lower $\mathrm{Fe}$ (higher Ta) concentrations with decreasing temperature.

(c) The inter-dendritic region (dark contrast) is $\mu$ phase following from the composition measured at a number of locations within this region (Table II) and the solidus projection. ${ }^{[22,23]}$ The fine lamellae preclude composition measurements because of volume averaging effects, ${ }^{[24]}$ but the coarsened island morphology corresponds to $\sigma$ phase. The composition of $\mu$ phase lies within the single-phase region in the solidus projection 
Table III. Average Composition of Phases with Standard Deviation in S3 and S4 (in Atom Percent)

\begin{tabular}{lcrr}
\hline Phase & Pct Al & Pct Co & Pct Nb \\
\hline CoAl (S3) & $44.8 \pm 0.48$ & $49.6 \pm 0.15$ & $5.6 \pm 0.33$ \\
C14 (S3) & $35.0 \pm 0.72$ & $35.0 \pm 0.82$ & $30.1 \pm 1.24$ \\
C14 (S4) & $35.9 \pm 0.13$ & $31.8 \pm 0.21$ & $32.3 \pm 0.17$ \\
CoAl (S4) & $41.7 \pm 1.43$ & $48.2 \pm 1.09$ & $10.1 \pm 1.04$ \\
\hline
\end{tabular}

Table IV. Average Composition of Phases with Standard Deviation in S5 (in Atom Percent)

\begin{tabular}{lccr}
\hline Phase & Pct Al & Pct Fe & Pct Nb \\
\hline $\mathrm{NbAl}_{3}$ & $74.7 \pm 0.05$ & $0.6 \pm 0.14$ & $24.7 \pm 0.18$ \\
$\mathrm{Nb}_{2} \mathrm{Al}+\mathrm{C} 14$ & $48.3 \pm 0.30$ & $8.3 \pm 0.25$ & $43.4 \pm 0.06$ \\
$\mathrm{Nb}_{2} \mathrm{Al}+\mathrm{C} 14+\mathrm{NbAl}_{3}$ & $54.5 \pm 0.96$ & $6.1 \pm 0.21$ & $39.4 \pm 0.76$ \\
\hline
\end{tabular}

(Figure 2(c)). However, since the $\mu /[\mu+\mathrm{A} 2]$ phase boundary moves towards higher Fe concentration with decreasing temperature, the change in solute solubility within $\mu$ phase during subsequent cooling cannot be neglected. It is worth emphasizing that in Table II, the two phases occurring in this alloy have Al contents of 16.1 ( $\sigma$ phase) and 20.0 at. pct ( $\mu$ phase), both of which are lower than the nominal value, 20.3 at. pct given in Table I. The latter was measured at low magnification, typically $\times 50$ over a series of locations across the cross section. Since the composition of $\sigma$ phase (Al-rich) was only measured in the coarse island-type morphology, it can be concluded that the fine lamellar morphology must be enriched in $\mathrm{Al}$ compared with the coarse morphology.

The solidification sequence is therefore, $L \rightarrow \sigma+L$ and $L \rightarrow \sigma+\mu$. The extent of primary solidification of $\sigma$ is very limited and followed by a eutectic reaction. Initial eutectic freezing is accompanied by a divorced morphology followed by coupled growth. The divorced morphology preceding coupled growth corresponds to a halo of $\mu$ phase around primary $\sigma$ phase.

S2 The solidification path of S2 is expected to follow, $L \rightarrow \sigma+L$ and $L \rightarrow \sigma+\mu$, following from the liquidus and solidus projections. ${ }^{[22,23]}$ Figures $3(\mathrm{a})$ and (b) are low- and high-magnification BEI's, respectively, from which the following observations can be made:

(a) There is the occurrence of the primary phase (bright contrast) having an irregularly shaped morphology and the inter-dendritic (ID) region comprises a dark phase.

(b) The primary phase corresponds to $\sigma$, following from the composition measured at a number of locations across the primary phase (Table II) and the solidus projection. ${ }^{[2,23]}$ An extended solubility of primarily $\mathrm{Fe}$ is observed in $\sigma$ from the solidus projection, as shown in Figure 3(c), which like in $\mathrm{S} 1$ cannot be accounted by solubility changes occurring during cooling. (c) The inter-dendritic region (dark contrast) is $\mu$ phase following from the composition measured at a number of locations within this region (Table II) and the solidus projection. ${ }^{[22,23]}$ The composition of $\mu$ phase lies within the single-phase field in the solidus projection (Figure 3(c)). However, since the $\mu /[\mu+\mathrm{A} 2]$ phase boundary moves towards higher Fe concentration with decreasing temperature, the change in solute solubility within $\mu$ phase during subsequent cooling cannot be neglected.

The solidification sequence is therefore, $L \rightarrow \sigma+L$ and $L \rightarrow \sigma+\mu$. Primary solidification of $\sigma$ is followed by a eutectic reaction with a divorced morphology. The divorced morphology preceding coupled growth corresponds to a halo of $\mu$ phase around primary $\sigma$ phase, which is more prominent in S2 compared with $\mathrm{S} 1$.

S3 The solidification path of S3 is expected to follow, $L \rightarrow \mathrm{CoAl}+L$ and $L \rightarrow \mathrm{CoA} 1+\mathrm{C} 14$, following from the liquidus projections and isothermal sections. ${ }^{[25-27]}$ Figure 4(a) is a low magnification, while Figures 4(b) and (c) are high-magnification BEI's from which the following observations can be made:

(a) The primary phase (dark) is dendritic/flaky. The inter-dendritic (ID) region comprises a thin rim or halo of the secondary phase (white) that surrounds the primary phase and a fine lamellar morphology that emanates from the halo. In the terminal stages of freezing, there is a progressive coarsening of the lamellar morphology, specifically at the boundary between two adjacent abutting eutectic cells.

(b) The primary flaky phase is CoAl following from the composition measured at a number of locations (Table III) and the isothermal projections at a series of temperatures. ${ }^{[2-27]}$ The measured composition lies on the $\mathrm{CoAl} /[\mathrm{CoAl}+\mathrm{C} 14]$ phase boundary, as observed in the isothermal sections at lower temperatures: $800{ }^{\circ} \mathrm{C}$ and $1200{ }^{\circ} \mathrm{C}$, and there is clear evidence of a change in solute solubility during cooling: $1477^{\circ} \mathrm{C}$ and $1492{ }^{\circ} \mathrm{C}$ (Figure $4(\mathrm{~d})$ ). In the absence of a solidus 

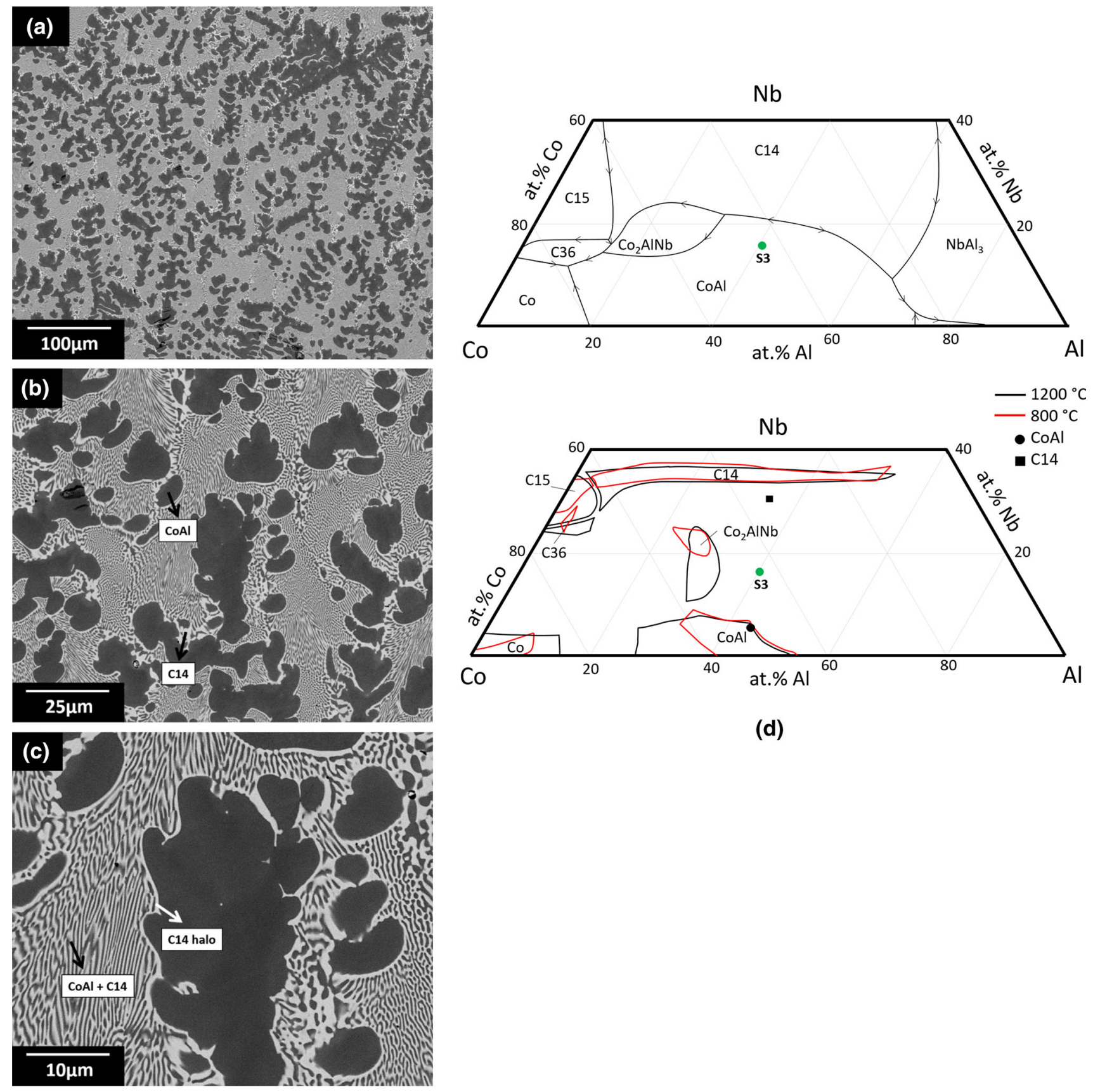

(d)

Fig. 4-Back-scattered electron images and liquidus projection and isothermal sections corresponding to S3, (a) low magnification, (b) and (c) high magnification, $(d)$ liquidus projection and isothermal sections showing phase boundaries with decreasing temperature in vicinity of CoAl and C14 phases. Also included is the measured composition in the phases. Reproduced with permission from Refs. [25] through [27].

projection and change in solute solubility it is not possible to ascertain the extent of any extended solute solubility in the primary phase.

(c) The composition measurements in the secondary phase are restricted to the coarser inter-dendritic morphology and the halo to minimize volume averaging effects (Table III) and corresponds to C14 following from the isothermal projections at a series of temperatures. ${ }^{[25-27]}$ However, the measured composition will have some degree of volume averaging with $\mathrm{CoAl}$, given the fine scale of the $\mathrm{C} 14$ phase, resulting in a lower measured $\mathrm{Nb}$ concentration. Consequently, the role of volume averaging cannot be discounted in the measured composition lying outside of the C14 phase field in the isothermal sections shown in Figure 4(d).

The solidification sequence is, $\mathrm{L} \rightarrow \mathrm{CoAl}+\mathrm{L}$ and $\mathrm{L} \rightarrow \mathrm{CoAl}+\mathrm{C} 14$. However, prior to the occurrence of coupled eutectic growth, there is the distinct formation of a halo of $\mathrm{C} 14$ phase on primary CoAl solid. 

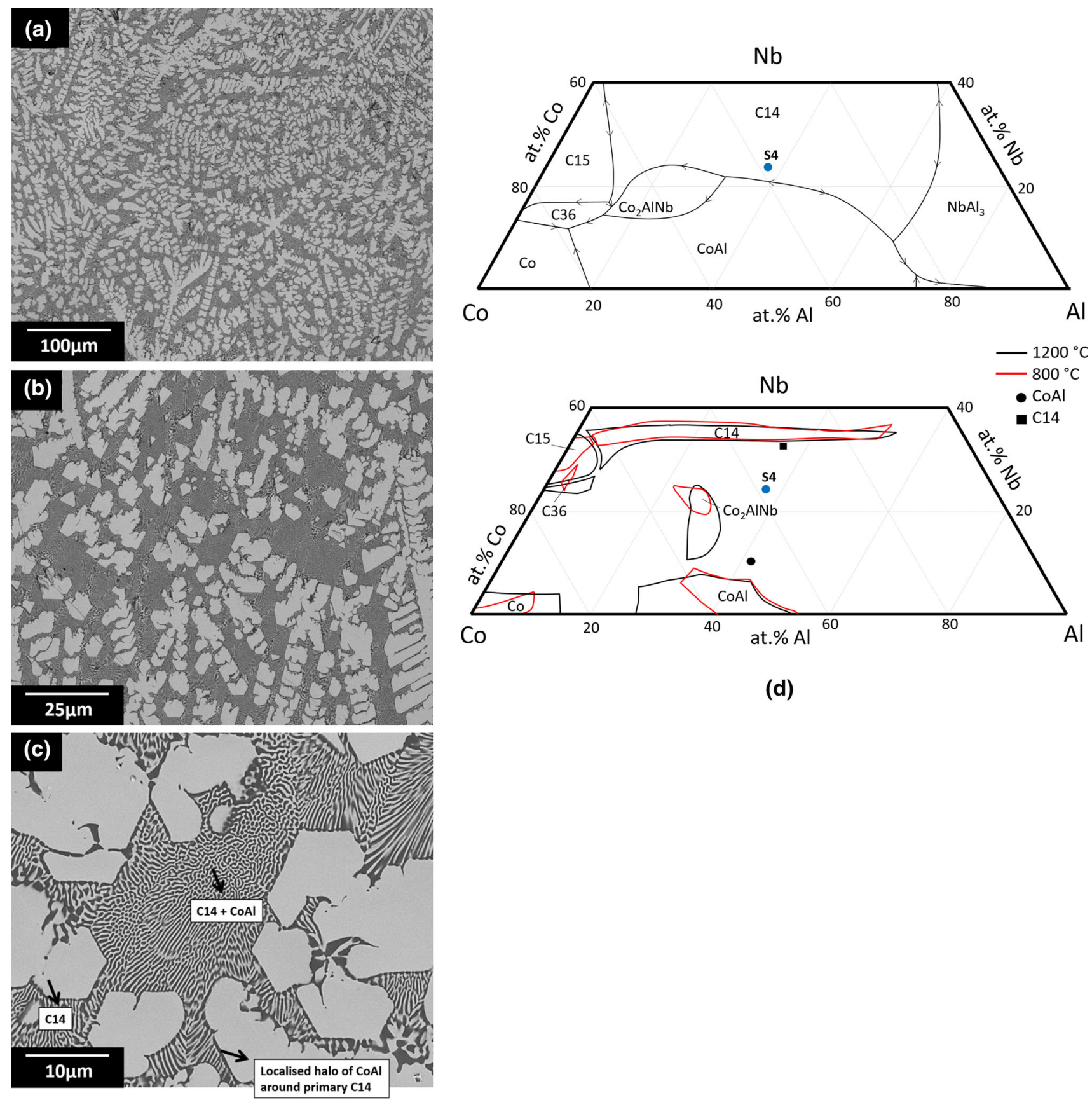

(d)

Fig. 5-Back-scattered electron images and liquidus projection and isothermal sections corresponding to S4, $(a)$ low magnification, $(b)$ and $(c)$ high magnification, $(d)$ liquidus projection and isothermal sections showing phase boundaries with decreasing temperature in vicinity of CoAl and $\mathrm{C} 14$ phases. Also included is the measured composition in the phases. Reproduced with permission from Refs. [25] through [27].

S4 The solidification path of S4 is expected to follow, $\mathrm{L} \rightarrow \mathrm{C} 14+\mathrm{L}$ and $\mathrm{L} \rightarrow \mathrm{C} 14+\mathrm{CoAl}$, following from the liquidus and isothermal sections. ${ }^{[25-27]}$ Figure 5(a) is a low magnification, while Figures 5(b) and (c) are high-magnification BEI's from which the following observations can be made:

(a) The primary phase (bright) shows a small degree of faceting. The inter-dendritic (ID) region comprises a fine lamellar morphology, with nucleation and growth of the dark phase. There is generally the absence of the halo on the primary phase and the lamellar morphology emanates directly from the primary phase. However, in some localized regions as indicated in Figure 5(c), a thin halo of $\mathrm{CoAl}$ around primary $\mathrm{C} 14$ can be discerned, but it is markedly less prominent compared to the halo of $\mathrm{C} 14$ formed around primary CoAl. In the terminal stages of freezing, there is some progressive coarsening of the lamellar morphology, specifically at the boundary between two adjacent abutting eutectic cells. 

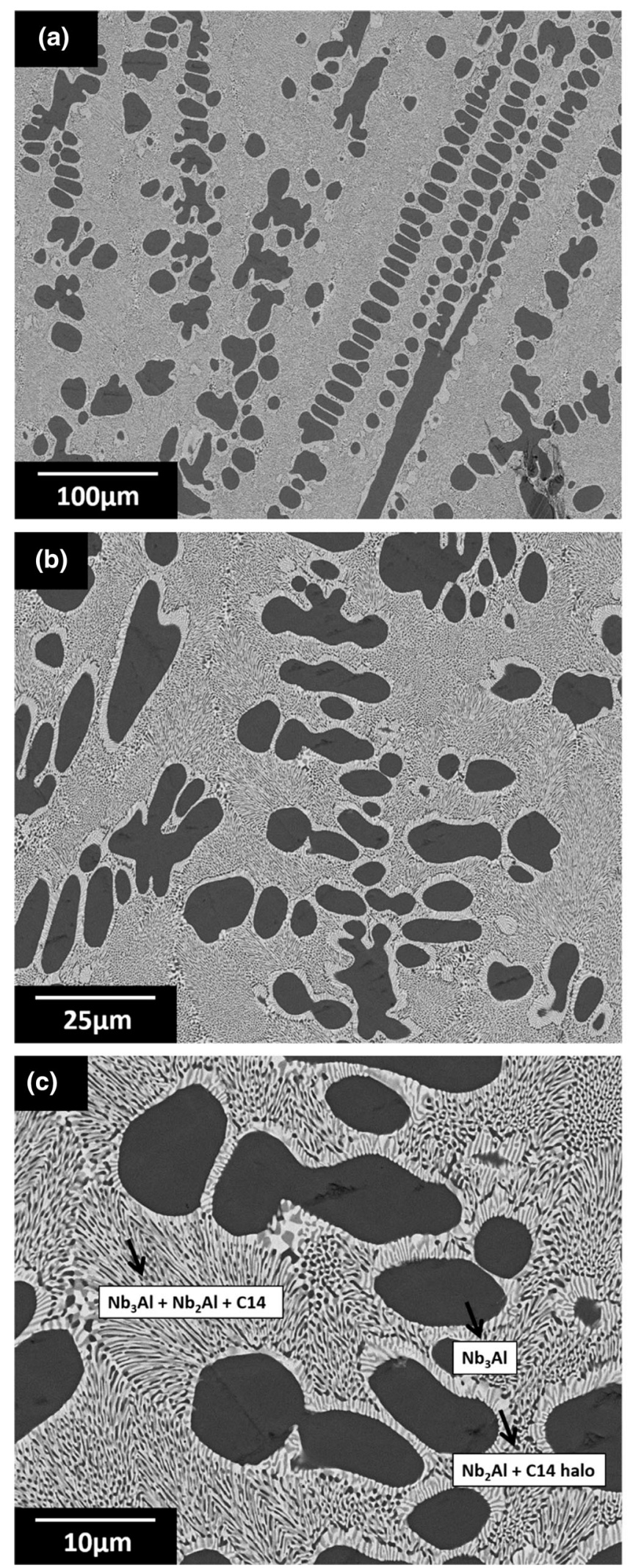
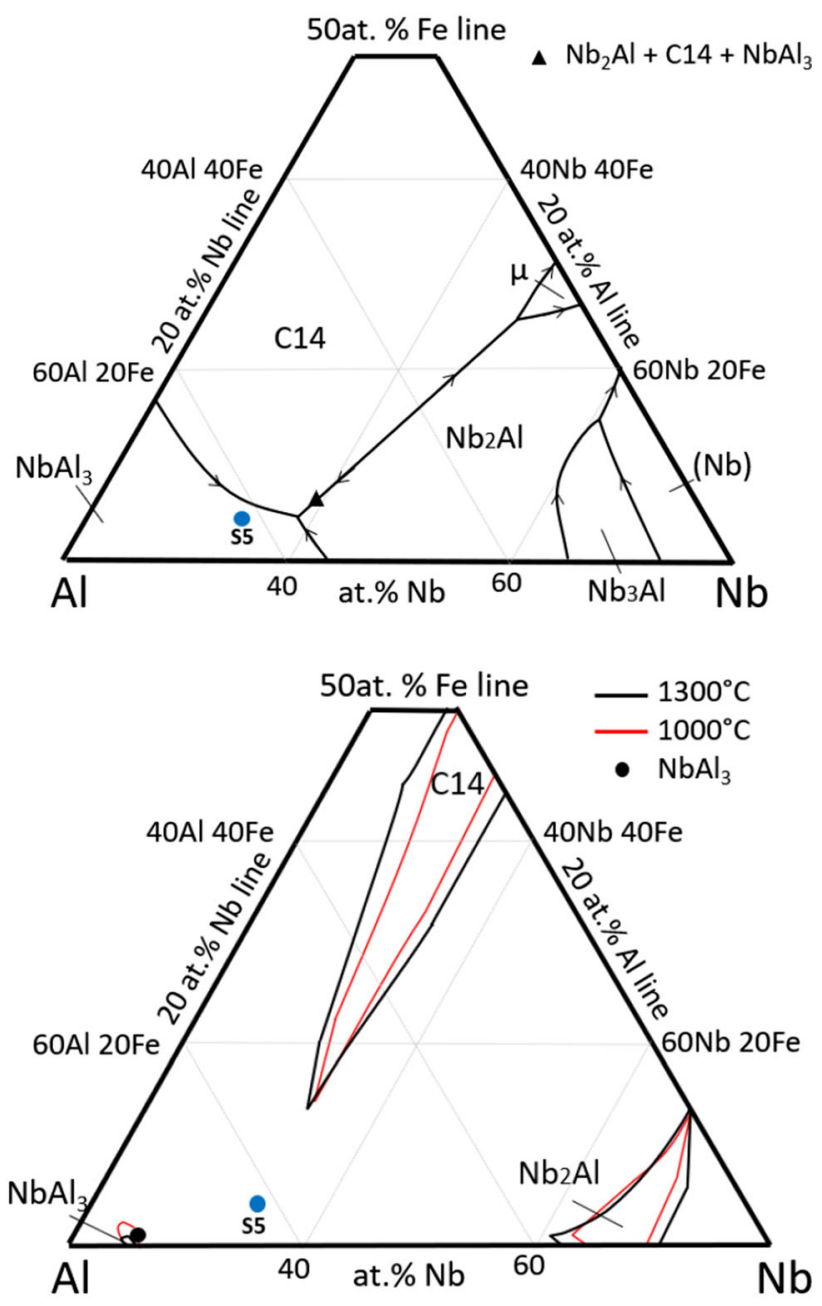

(d)

Fig. 6-Back-scattered electron images and liquidus projection and isothermal sections corresponding to S5, (a) low magnification, (b) and (c) high magnification, $(d)$ liquidus projection and isothermal sections showing phase boundaries with decreasing temperature in the Al-rich end. Also included is the measured composition in the phases. Reproduced with permission from Refs. [28] through [30]. 


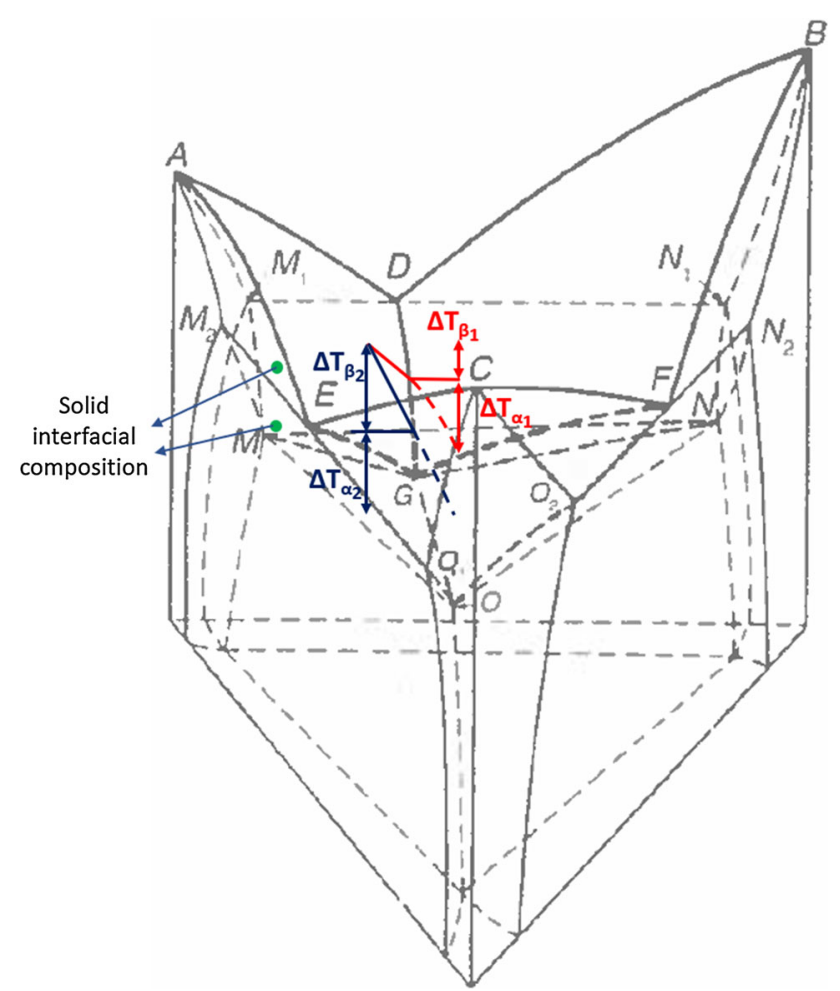

Fig. 7-Schematic of ternary diagram illustrating the liquid and solid compositions during eutectic growth, $L \rightarrow \alpha+\beta$. Undercooling associated with growth of halo $(\beta)$ phase is shown for two representative freezing paths (dotted red and black lines). Also indicated are the interfacial solid composition for primary $(\alpha)$ phase, which lies beyond solidus line $\mathrm{M}_{1} \mathrm{M}$ indicating extended solute solubility. Solute solubility changes during subsequent cooling are neglected. Reproduced with permission from Ref. [35].

(b) The primary phase is $\mathrm{C} 14$ following from the composition measured at a number of locations (Table III) and the isothermal sections. ${ }^{[25-27]}$ The measured composition lies on the $\mathrm{C} 14 /$ $[\mathrm{C} 14+\mathrm{CoAl}]$ phase boundary at $1492{ }^{\circ} \mathrm{C}$ (Figure $5(\mathrm{~d})$ ), but in the absence of a solidus projection it is not possible to ascertain the extent of any extended solute solubility in the primary phase.

(c) The composition measured (Table III) is restricted to the coarser inter-dendritic morphology to minimize volume averaging effects and corresponds to $\mathrm{CoAl}$ phase, following from the isothermal projections at a series of temperatures. ${ }^{[2-27]}$ The measured composition lies beyond the single-phase field, but given the fine morphology volume averaging is always prevalent in CoAl, resulting in a higher measured $\mathrm{Nb}$ concentration.

The solidification sequence is $L \rightarrow \mathrm{C} 14+L$ and $L \rightarrow \mathrm{C} 14+\mathrm{CoAl}$. Moreover, there is generally the absence of a halo of CoAl phase on primary $\mathrm{C} 14$ solid, although it is observed in some localized regions.
S5 The solidification path of $\mathrm{S} 5$ is expected to follow $L \rightarrow \mathrm{NbAl}_{3}+L, \quad L \rightarrow \mathrm{NbAl}_{3}+\mathrm{C} 14+L, \quad$ and $L \rightarrow \mathrm{NbAl}_{3}+\mathrm{Cl} 14+\mathrm{Nb}_{2} \mathrm{Al}$, following from the liquidus and solidus projections. ${ }^{[28-30]}$ Figure $6($ a) is a low magnification, while Figures 6(b) and (c) are high-magnification BEI's from which the following observations can be made:

(a) The primary phase (dark contrast) is dendritic. The inter-dendritic (ID) region comprises a fine lamellar morphology. The lamellar structure comprises two distinct types:

(i) There is a lamellar structure that emanates from the primary solid constituting a two-phase halo. The halo can be justified on the basis that none of the two lamellar constituents (bright and gray) constitute the primary phase.

(ii) Beyond the initial two-phase halo, further growth corresponds to a ternary eutectic with the nucleation and growth of the primary phase, as the third constituent in the eutectic.

(b) The primary phase corresponds to $\mathrm{NbAl}_{3}$ following composition measurements at a number of locations and the isothermal projections at a series of temperatures, as shown in Figure 6(d).

(c) The fine lamellar morphology precludes accurate composition measurements. However, given the regular morphology of the eutectic, average compositions were measured within both the twophase (halo) and three-phase morphologies. The measured composition in the two-phase halo lies in the two-phase $\mathrm{Nb}_{2} \mathrm{Al}+\mathrm{C} 14$ phase field, indicating that the halo corresponds to coupled growth of $\mathrm{Nb}_{2} \mathrm{Al}+\mathrm{C} 14 .^{[28]}$ The ternary eutectic corresponds very closely to the invariant point in the liquidus projection involving $\mathrm{NbAl}_{3}, \mathrm{Nb}_{2} \mathrm{Al}$, and $\mathrm{C} 14,{ }^{[28-30]}$ as shown in Figure 6(d).

The solidification sequence is $L \rightarrow \mathrm{NbAl}_{3}+L$, $L \rightarrow \mathrm{Nb}_{2} \mathrm{Al}+\mathrm{C} 14+L$, and $L \rightarrow \mathrm{Nb}_{2} \mathrm{Al}+\mathrm{C} 14+$ $\mathrm{NbAl}_{3}$, which is not as expected from the phase diagram (Table IV).

\section{DISCUSSION}

Unlike in the binary phase diagram where the "partition coefficient $(k)$ " is fixed at a given temperature during primary freezing, this is not the case in ternary systems since an added degree of freedom exists. For conservation of solute during primary freezing in an incremental temperature interval, $d T$ or time interval $d t$,

$$
\begin{aligned}
& {\left[C_{\infty B}-C_{S B}\right] d f_{S}=\int D_{S} \frac{d C_{S B}}{d x} d t+\left(1-f_{S}\right) d C_{\infty B}, \quad[1 \mathrm{a}]} \\
& {\left[C_{\infty C}-C_{S C}\right] d f_{S}=\int D_{S} \frac{d C_{S C}}{d x} d t+\left(1-f_{S}\right) d C_{\infty C}, \quad[1 \mathrm{~b}]}
\end{aligned}
$$


where the new solute composition in the liquid at $[T-\Delta T]$ is given by $\left[C_{\infty B}+d C_{\infty B}\right]$ and $\left[C_{\infty C}+d C\right], d f_{S}$ is the incremental fraction solid and $D_{S}$ is the solute diffusivity in the solid. For small undercooling $\mathrm{S} / \mathrm{L}$ interfacial equilibrium exists and therefore there are only two unknowns in Eqs. [1a] and [1b], i.e., $d f_{S}$ and $d C_{\infty \mathrm{B}}\left(\right.$ or $\left.d C_{\infty \mathrm{C}}\right)$. Therefore, the extent of back-diffusion will govern the extent of incremental solid growth $\left(d f_{S}\right)$ and the composition in the liquid. ${ }^{[31-33]}$ This is schematically illustrated in Figure 7, where two representative paths taken by the liquid over the liquidus surface during primary freezing is indicated. Accordingly, the liquid composition intersects the eutectic valley (DG) at two different points at the end of primary solidification depending on the path followed, as governed by the kinetics of back-diffusion.

At the end of primary growth the evolution of the secondary $(\beta)$ phase morphology will be determined by the local undercooling. Accordingly, let $\left(C_{\mathrm{B}}^{\mathrm{e}}, C_{\mathrm{C}}^{\mathrm{e}}\right)$ correspond to the liquid composition in the eutectic valley at temperature $T$ (at end of primary growth) and because of undercooling the composition of the liquid into which $\beta$ phase grows is $\left(C_{\infty \mathrm{B}}, C_{\infty \mathrm{C}}\right)$ and $\left(C_{\mathrm{B}}^{\mathrm{e}}, C_{\mathrm{C}}^{\mathrm{e}}\right) \neq\left(C_{\infty \mathrm{B}}\right.$, $C_{\infty \mathrm{C}}$ ). Using Figure 1 but extrapolating to a ternary system, the net undercooling with which $\beta$ (halo) phase grows is then,

$$
\begin{aligned}
& {\left[-m_{\alpha B}\left(C_{\infty B}-C_{B}^{e}\right)-m_{\alpha C}\left(C_{\infty C}-C_{C}^{e}\right)\right]} \\
& \quad+\left[m_{\beta B}\left(C_{B}^{e}-C_{\infty B}\right)+m_{\beta C}\left(C_{C}^{e}-C_{\infty C}\right)\right]=\frac{G D}{V}+k \sqrt{V}
\end{aligned}
$$

when the curvature term is neglected and both bracketed terms on the LHS of Eq. [2] are positive. The subscripts refer to $\alpha$ and $\beta$ phase, $m_{\alpha \cdot B}=\left(\frac{\partial T}{\partial C_{B}}\right)$ const $C<0$, etc. The first bracketed term on the LHS of Eq. [2] is the undercooling below the eutectic valley and the second bracketed term is the undercooling at the eutectic valley with respect to local $\beta$ liquidus temperature, as shown in Figure 7. Following the approach in Reference 34 in case of 3-phase planar eutectic growth $(L, \alpha$ and $\beta)$, the corresponding undercooling for coupled eutectic growth can also be determined. Like in the binary case for a given undercooling, a halo of $\beta$ phase forms around primary $\alpha$, if $V>V^{\prime}$, following the terminology defined previously. Importantly from the preceding arguments in a ternary system, the solidification path will play a prominent role in the formation of halos, since it defines $\left(C_{\mathrm{B}}^{\mathrm{e}}, C_{\mathrm{C}}^{\mathrm{e}}\right)$, i.e., it defines the point where the liquid composition intersects the eutectic valley, as illustrated in Figure 7.

In the Ta-Al-Fe system, $\alpha$ corresponds to $\sigma$ phase and $\beta$ corresponds to $\mu$ phase. The liquidus temperature of both S1 and S2 is approximately $2100 \mathrm{~K}\left(1827{ }^{\circ} \mathrm{C}\right)$, as deduced from the liquidus projection in References 22 and 23, but as observed in Figures 2(c) and 3(c) following primary solidification of $\sigma$, the path followed by the liquid composition along the $\sigma-\mu$ eutectic valley during the eutectic reaction, $L \rightarrow \sigma+\mu$ is different in the two cases. This is because the line joining the average solid $(\sigma)$ composition and the nominal composition following primary freezing intersects the $\sigma-\mu$ eutectic valley, on either side of the maximum $\left(e_{1}\right)$ in References 22 and 23. When coupled eutectic growth is observed following the formation of an initial halo (S1), the liquid composition intersects the eutectic valley defined by $\mathrm{e}_{1}$ $U_{1}$ (where $U_{1}$ is the quasi-peritectic point in the Al-lean end), while when there is no coupled growth (S2) the liquid composition intersects the "eutectic valley" defined by e $U_{2}$ (where $U_{2}$ is the quasi-peritectic point in the Al-rich end). This confirms that the solidification path:

(a) Initially dictates the traverse of the liquid composition on the liquidus surface during primary freezing and determines the point of intersection of the liquid composition with the eutectic valley, $\left[C_{B}^{e}, C_{C}^{e}\right]$.

(b) It also determines the liquid composition, [ $C_{\infty B}$, $C_{\infty C}$ ] into which the halo grows and which determines the phase morphologies that evolve.

Since it is not possible to easily measure the undercooling, it is important to note that since undercooling occurs below the eutectic temperature it must lead to an extended solute solubility within the primary phase through $m_{\sigma F e}$ and $m_{\sigma T a}$. It is easier therefore to measure this extended solute solubility in the solid. However as a point of caution, it must also be emphasized that changes in solute solubility can also occur during cooling. Nevertheless it can be observed from Figures 2(c) and 3(c) that an extended solubility of at least $\sim 2$ at. pct $\mathrm{Fe}$ is observed in $\sigma$ phase in both $\mathrm{S} 1$ and $\mathrm{S} 2$, given that the measured composition lies outside of the single-phase field. It must also be pointed out that the coupled eutectic growth morphology comprises individual cells, which grow and abut into each other in $\mathrm{S} 1$ and arises from a long-range diffusion boundary layer is built-up above the composite $\mathrm{S} / \mathrm{L}$ interface. Therefore coupled eutectic growth does not occur with a planar front, but comprises cells.

Another point pertaining to primary freezing in S1 and $\mathrm{S} 2$ is worth mentioning. In $\mathrm{S} 1$ the nominal composition lies almost on the eutectic valley; nevertheless a noticeable amount of primary $\sigma$ is observed. A possible explanation is that the location of the $\sigma-\mu$ eutectic valley in the liquidus projection in the vicinity of $\mathrm{S} 1$ is inaccurate. ${ }^{[22,23]}$ It should be slightly displaced to the right in Figure 3(c), so that the nominal composition is further displaced from the eutectic valley.

In the Nb-Al-Co system, a thin halo of $\mathrm{C} 14$ is observed around primary CoAl (S3) but very limited vice versa $(\mathrm{S} 4)$. The approximate liquidus temperature of $\mathrm{S} 3$ is $1818 \mathrm{~K}\left(1545^{\circ} \mathrm{C}\right)$ and $\mathrm{S} 4$ is $1841 \mathrm{~K}\left(1568{ }^{\circ} \mathrm{C}\right)$, as deduced from the liquidus projection ${ }^{[25]}$ and solidification must terminate before the peritectic reaction, $\mathrm{L}+\mathrm{C} 14+\mathrm{CoAl} \rightarrow \mathrm{Co}_{2} \mathrm{AlNb}$, occurs at $1755 \mathrm{~K}$ $\left(1482{ }^{\circ} \mathrm{C}\right)$. There is no reported solidus projection and the highest temperature isothermal projection is 
$\left(1492^{\circ} \mathrm{C}\right) .{ }^{[27]}$ Noting that there is very little change in the profile of the $\mathrm{CoAl} /[\mathrm{CoAl}+\mathrm{C} 14]$ boundary in the composition range 35 at. pet $<\mathrm{Al}<55$ at. pet and $0<\mathrm{Nb}<8$ at. pct and the CoAl composition in S4 lies on the boundary (Figure $4(\mathrm{~d})$ ) in the temperature range $\left(800{ }^{\circ} \mathrm{C}\right.$ to $\left.1200{ }^{\circ} \mathrm{C}\right)$, in the absence of a solidus projection and a clear change in solute solubility in the temperature range $\left(1477{ }^{\circ} \mathrm{C}\right.$ to $\left.1492^{\circ} \mathrm{C}\right)$, no definitive assertions about the existence of any extended solute solubility in CoAl can be made. ${ }^{[26,27]} \mathrm{A}$ similar situation exists when C14 is the primary phase in S5. Although the measured composition of $\mathrm{C} 14$ lies outside the single-phase field, in the absence of a solidus projection an extended solute solubility in C14 cannot be definitively confirmed. However, the very thin halo $(<2 \mu \mathrm{m})$ indicates that the halo phase grows at a lower undercooling compared with that in S1 and S2. With progressively decreasing undercooling accompanying growth of $\mathrm{C} 14$ halo phase, coupled eutectic growth is rapidly established. Like in the Ta-Al-Fe case, the coupled morphology comprises individual cells, which grow and abut into each other indicating a de-stabilization of both constituent phases.

In the preceding analysis given the restricted extended solute solubility, it was reasonable to use the assumption of equilibrium at the $\mathrm{S} / \mathrm{L}$ interface. However, in some cases, the eutectic phases grow at large undercooling and there is departure from equilibrium. This mainly arises from nucleation constraints and is observed in S5 in the $\mathrm{Nb}-\mathrm{Al}$-Fe system. The liquidus temperature of S5 is approximately $1600{ }^{\circ} \mathrm{C}(1873 \mathrm{~K})$, as deduced from the liquidus projection in References 28 through 30 and the nominal composition is located almost on the $\mathrm{NbAl}_{3}-\mathrm{C} 14$ eutectic valley, which indicates very limited primary solidification. The positioning of the eutectic valley in the vicinity of S5 is also correct, since the measured composition of the 3 -phase eutectic $\left[\mathrm{NbAl}_{3}+\right.$ $\mathrm{C} 14+\mathrm{Nb}_{2} \mathrm{All}$ corresponds very closely to that of the invariant 4-phase eutectic reaction in the liquidus projection (Figure 6(d)). Therefore the notable presence of primary $\mathrm{NbAl}_{3}$ (Figure 6(a)) indicates that growth of C14 either as a halo or as coupled eutectic requires significant undercooling. This results in the liquid composition departing significantly from the $\mathrm{NbAl}_{3}-\mathrm{Cl}$ eutectic valley and continuing on the metastable $\mathrm{NbAl}_{3}$ liquidus surface. The continued primary growth of $\mathrm{NbAl}_{3}$ leads to depletion of $\mathrm{Al}$ in the liquid. The corresponding solid compositions will also lie beyond the solidus surface bounded by $M_{1} M$, as shown in Figure 7, when the primary phase shows solute solubility. However since $\mathrm{NbAl}_{3}$ is a stoichiometric compound, this is not the case here. In the case of significant undercooling when the extended liquidus surface lies below the $\mathrm{Nb}_{2} \mathrm{Al}-\mathrm{C} 14$ eutectic valley for the corresponding liquid composition, either $\mathrm{Nb}_{2} \mathrm{Al}$ or $\mathrm{C} 14$ or both phases can nucleate on the primary solid. The coupled growth of $\mathrm{Nb}_{2} \mathrm{Al}+\mathrm{C} 14$ constituting a two-phase halo implies that $\mathrm{Nb}_{2} \mathrm{Al}+\mathrm{C} 14$ coupled eutectic must grow at a smaller undercooling than either $\mathrm{NbAl}_{3}+\mathrm{Cl} 4$ coupled eutectic, $\mathrm{NbAl}_{3}+\mathrm{Nb}_{2} \mathrm{Al}$ coupled eutectic, $\mathrm{C} 14$ halo, or $\mathrm{Nb}_{2} \mathrm{Al}$ halo on primary $\mathrm{NbAl}_{3}$, as also observed in Reference 28. The growth of the halo phase is then followed by the invariant eutectic reaction, $L \rightarrow \mathrm{Nb}_{2} \mathrm{Al}+\mathrm{C} 14+\mathrm{NbAl}_{3}$.

Finally, it is worth emphasizing in these experiments that because of the small size of sample, large thermal gradients are achieved. For larger samples, the cooling rates $(V)$ are lower but at the same time there is also a lower directional heat flux $(G)$. Consequently in the case of halo growth it is not straightforward to qualitatively ascertain the change in the term $\frac{G D}{V}$ in Eq. [2]. When this term dominates, halo growth is restricted since for a given velocity the secondary phase grows with a higher undercooling compared to that for the coupled eutectic.

\section{CONCLUSIONS}

Secondary phase morphologies following primary solidification has been studied in the Ta-Al-Fe, $\mathrm{Nb}-\mathrm{Al}-\mathrm{Co}$, and $\mathrm{Nb}-\mathrm{Al}-\mathrm{Fe}$ ternary systems. The following conclusions can be made:

(1) The undercooling accompanying solid growth is related to the extended solute solubility in the primary and secondary phases and can be used to account for the evolution of phase morphologies during ternary eutectic solidification.

(2) In Ta-Al-Fe system, there occurs an extended solubility of $\mathrm{Fe}$ in $\sigma$ phase, which was consistent with the formation of a halo of $\mu$ phase on primary $\sigma$ phases.

(3) In $\mathrm{Nb}-\mathrm{Al}$-Co system, halo of $\mathrm{C} 14$ is formed on primary $\mathrm{CoAl}$, but very limited vice versa. In the absence of a solidus projection it was not possible to definitively determine the extended solute solubility in the primary phase.

(4) Nucleation constraints result in large undercooling and departure from equilibrium conditions and leading to the occurrence of halos. In $\mathrm{Nb}-\mathrm{Al}$-Fe system, extended primary freezing of $\mathrm{NbAl}_{3}$ is followed by a two-phase halo of $\mathrm{C} 14+\mathrm{Nb}_{2} \mathrm{Al}$ on primary $\mathrm{NbAl}_{3}$, before the ternary eutectic reaction.

\section{ACKNOWLEDGMENTS}

One of the authors (ND) would wish to acknowledge funding from the Accelerated Metallurgy Project, which was co-funded by the European Commission in the 7th Framework Programme (Contract NMP4-LA-2011-263206) and by the individual partner organizations. LMF would wish to thank CNPq for funding Ph.D. study. Dr. Nick Jones from University of Cambridge is acknowledged for his assistance in making the arc-melted samples. 


\section{OPEN ACCESS}

This article is distributed under the terms of the Creative Commons Attribution 4.0 International License (http://creativecommons.org/licenses/by/4.0/), which permits unrestricted use, distribution, and reproduction in any medium, provided you give appropriate credit to the original author(s) and the source, provide a link to the Creative Commons license, and indicate if changes were made.

\section{REFERENCES}

1. M.F.X. Gigliotti, Jr, G.A. Colligan, and G.L.F. Powell: Mater. Trans., 1970, vol. 1, pp. 891-97.

2. M. McLean: Directionally Solidified Materials for High Temperature Service, The Metal Society, Pittsburgh, 1983, p. 55.

3. P. Cerba, M. Vilasi, B. Malaman, and J. Steinmetz: J. Alloys Compd, 1993, vol. 201, pp. 57-60.

4. G. Ghosh and G.B. Olson: Acta Mater., 2007, vol. 55, pp. 3281-3303.

5. H.T. Pang, N. D'Souza, H.B. Dong, H.J. Stone, and C.M.F. Rae: Met. Mater. Trans. A., 2016, vol. 47A, pp. 889-906.

6. N. D'Souza, S. Simmonds, G.D. West, and H.B. Dong: Met. Mater. Trans. A., 2013, vol. 44A, pp. 4764-73.

7. G Brewster, N D'souza, KS Ryder, S Simmonds, and HB Dong: Met Mater Trans A, 2012, vol. 43, pp. 1288-1302.

8. G. Sauthoff: Intermetallics, 2008, vol. 8, pp. 469-81.

9. L. Machon and G. Sauthoff: Intermetallics, 1996, vol. 4, pp. 1101-09.

10. BE Sundquist, R Bruscato, and LF Mondolfo: J. Inst. Met., 1962, vol. 91, p. 204

11. W Kurz and DJ Fisher: Fundamentals of Solidification, Trans Tech Publications Ltd, Stafa zurich, 1986, pp. 134-36.

12. M.H. Burden and J.D. Hunt: J. Cryst. Growth, 1974, vol. 22, pp. $109-16$.

13. K. A. Jackson, J. D. Hunt, Trans. Met. Soc., AIME, 1966, Vol. 236, pp. 1129-42.

14. J. D. Hunt, S-Z Lu, Handbook of Crystal Growth, 1994, Vol. 2. Ed. D. T. J. Hurle, pp. 1113-66.
15. M.D. Nave, A.K. Dahle, and D.H. StJohn: Acta Mater., 2002, vol. 50, pp. 2837-49.

16. S.M. Li, B.L. Jiang, B.L. Ma, and H.Z. Fu: J. Cryst. Growth, 2007, vol. 299, pp. 178-83.

17. K.W. Li, X.B. Wang, C.M. Li, W.X. Wang, S.P. Chen, D.Q. Gong, and L.L. Cui: High Temp. Mater. Proc., 2015, vol. 34, pp. 479-85.

18. K.W. Li, S.M. Li, Y.L. Xue, and H.Z. Fu: J. Cryst. Growth, 2012, vol. 357 , pp. $30-34$.

19. N. D'Souza, L.M. Feitosa, G.D. West, N.G. Jones, and H.B. Dong: J. Alloy Comp., 2017, vol. 398, pp. 375-83.

20. L.M. Feitosa, N. D'Souza, G.D. West, and H.B. Dong: Met. Mater. Trans. A., 2017, vol. 48A, pp. 3811-14.

21. D. Welton, N. D'Souza, J. Kelleher, S. Gardner, Z.H. Dong, G.D. West, and H.B. Dong: Met. Mater. Trans. A., 2015, vol. 46A, pp. $4298-15$.

22. V. Raghavan: J. Phase Eqlb. Diff., 2013, vol. 34, pp. 328-49.

23. V.T. Witusiewicz et al.: J. Mat. Sci., 2013, vol. 48, pp. 377-12.

24. N. D'Souza, R. Beanland, C. Hayward, and H.B. Dong: Acta Mater., 2011, vol. 59, pp. 1003-13.

25. M. Palm, C. He, O. Dovbenko, F. Stein, and J.C. Schuster: $J$. Phase Eqlb. Diff., 2012, vol. 33, pp. 210-21.

26. O. Dovbenko, F. Stein, M. Palm, and O. Prymak: Intermetallics, 2010, vol. 18, pp. 2191-2207.

27. C. He, F. Stein, and M. Palm: J. All. Comp., 2015, vol. 637, pp. 361-75.

28. F. Stein, C. He, and O. Prymak: S. Vo $\beta$, I. WossackIntermetallics, 2015 , vol. 59 , pp. $43-58$.

29. C. He, Y. Qin, F. Stein, J. Phase. Eqlb., Diff., 2017, Vol. 38, pp. $771-87$.

30. C. Guo, T. Wu, C. Li, Z. Du, CALPHAD, 2107, vol. 57, pp. $78-87$.

31. W. J. Boettinger, U. R. Kattner, D. K. Banerjee, Modelling and Casting of Advanced Solidification Processes (MCWASP), VIII, Eds. B. G. Thomas, C. Beckermann, TMS, 1998, pp. 159-70.

32. E.C. Kurum, H.B. Dong, and J.D. Hunt: Met. Mater. Trans. A, 2005, vol. 36A, pp. 3103-10.

33. N. D'Souza and H.B. Dong: Scripta Materialia, 2007, vol. 56, pp. $41-44$

34. D.G. McCartney, J.D. Hunt, and R.M. Jordan: Met. Mater. Trans. A, 1980, vol. 11A, pp. 1243-49.

35. DRF West and N Saunders: Ternary Phase Diagrams in Materials Science, 3rd ed., Maney Publishing, Leeds, 2002, pp. 67-68. 